\title{
Characterization and Transcriptional Analysis of the Gene Cluster for Coronafacic Acid, the Polyketide Component of the Phytotoxin Coronatine
}

\author{
H. LIYANAGE, D. A. PALMER, M. ULLRICH, AND C. L. BENDER* \\ Department of Plant Pathology, Noble Research Center, Oklahoma \\ State University, Stillwater, Oklahoma 74078-3032
}

Received 29 June 1995/Accepted 8 September 1995

\begin{abstract}
Coronafacic acid (CFA), the polyketide component of the phytotoxin coronatine (COR), is activated and coupled to coronamic acid via amide bond formation, a biosynthetic step presumably catalyzed by the CFA ligase ( $c f)$ gene product. The COR biosynthetic gene cluster in Pseudomonas syringae pv. glycinea PG4180 is located within a $32-\mathrm{kb}$ region of a $90-\mathrm{kb}$ plasmid designated $\mathrm{p} 4180 \mathrm{~A}$. In the present study, a cloned region of p4180A complemented all $\mathrm{CFA}^{-}$mutants spanning an 18.8 -kb region of the COR biosynthetic cluster. The genetic evidence presented in this study indicates that $c f$ and the CFA biosynthetic gene cluster are encoded by a single transcript and that transcription of all of the genes in this operon is directed by the $c f$ promoter. The $c f$ promoter was localized to a $0.37-\mathrm{kb}$ region upstream of the transcriptional start site by progressive subcloning in pRG960sd, a vector containing a promoterless glucuronidase gene. Transcription of the $c f / \mathrm{CFA}$ operon was temperature sensitive and showed maximal glucuronidase activity at $18^{\circ} \mathrm{C}$. Furthermore, transcription of the $c f / C F A$ operon was dependent on the functional activity of a modified two-component regulatory system located within the COR biosynthetic gene cluster. Thermoregulation of the $c f / C F A$ operon and the coronamic acid biosynthetic gene cluster via the modified two-component regulatory system is discussed.
\end{abstract}

Biosynthesis of the phytotoxin coronatine (COR) in the phytopathogen Pseudomonas syringae involves amide bond formation between two distinct intermediates in the COR pathway, coronafacic acid (CFA), a bicyclic hydrindanone carboxylic acid, and coronamic acid (CMA), which is 2-ethyl-1-aminocyclopropane 1-carboxylic acid $(15,20,21)$. CFA is derived from the polyketide pathway and originates from three acetate units and one unit each of butyrate and pyruvate (21). The biosynthesis of CMA initially involves the isomerization of L-isoleucine to L-alloisoleucine, which is presumably followed by an oxidative cyclization to form the cyclopropane ring $(19,21)$.

In $P$. syringae pv. glycinea PG4180, the COR biosynthetic cluster is located within a $32-\mathrm{kb}$ contiguous region of a $90-\mathrm{kb}$ plasmid designated p4180A (1). Extensive mutational analysis, as well as the cloning, expression, nucleotide sequencing, and transcriptional mapping of several genes required for COR production $(1,13,25,27)$, has resulted in the development of a functional map of the COR biosynthetic gene cluster (Fig. 1A). These studies have indicated a clustering of the genes for CMA and CFA biosynthesis at opposing ends of the COR biosynthetic gene cluster (Fig. 1A). Transposon insertions in the CMA and CFA biosynthetic regions resulted in mutants with $\mathrm{CMA}^{-} \mathrm{CFA}^{+}$and $\mathrm{CMA}^{-} \mathrm{CFA}^{+}$phenotypes; these could be complemented when exogenous CMA or CFA, respectively, was supplied to the bacterial cultures $(1,27)$. Recently, the DNA region believed to be involved in the coupling (CPL) of CFA and CMA via amide bond formation was cloned, sequenced, and overexpressed in Escherichia coli $(1,13)$. Sequence analysis of this $2.37-\mathrm{kb}$ region revealed the presence of a single gene encoding coronafacate ligase $(c f l)$. The predicted protein product of $c f l$ showed relatedness to enzymes which

\footnotetext{
* Corresponding author. Mailing address: 110 Noble Research Center, Oklahoma State University, Stillwater, OK 74078-3032. Phone: (405) 744-9945. Fax: (405) 744-7373. Electronic mail address: CBENDER@ VMS.UCC.OKSTATE.EDU.
}

activate substrates for ligation via adenylation (adenylateforming enzymes) (13).

The CMA and CFA biosynthetic gene clusters are separated by a $4.3-\mathrm{kb}$ region in which mutations interrupt the production of both intermediates, suggesting a possible role for this region in the regulation of COR biosynthesis. Nucleotide sequencing of this region revealed the presence of three genes, corS, corR, and $\operatorname{cor} P$, which encode a modified two-component regulatory system consisting of one sensor protein, CorS, and two response regulator proteins, CorR and CorP (28). Transcriptional fusions to a promoterless glucuronidase (GUS) gene (uidA) indicated that $c m a A$ and $c m a T$, which are cotranscribed from the $c m a A$ promoter and required for CMA biosynthesis, were not expressed in $\operatorname{cor} S$, corR, or corP mutants (28).

COR production in $P$. syringae pv. glycinea PG4180 is temperature dependent with maximal amounts of COR, CFA, and CMA produced at $18^{\circ} \mathrm{C}$ and negligible amounts produced at 28 to $30^{\circ} \mathrm{C}(16,17,25)$. A cmaA::uid $A$ transcriptional fusion indicated that $18^{\circ} \mathrm{C}$ was an optimal temperature for transcription of the CMA biosynthetic cluster (25). Furthermore, the modified two-component regulatory system consisting of $\operatorname{cor} S$, corR, and $\operatorname{cor} P$ was shown to be required for the temperature-dependent activation of the cmaA::uidA transcriptional fusion (28).

The present study focused on transcriptional activation of the $c f l$ gene and the extent of DNA transcribed from the $c f$ promoter. Our specific objectives included the following: (i) determination of the minimal size of the $c f$ promoter, (ii) investigation of whether expression of the $c f l$ promoter is temperature dependent and controlled by the modified two-component regulatory system, and (iii) investigation of whether $c f l$ is cotranscribed with genes encoded by the CFA biosynthetic gene cluster.

\section{MATERIALS AND METHODS}

Bacterial strains, plasmids, media, and growth conditions. The bacterial strains and plasmids used in this study are listed in Table 1. E. coli HB101 and DH5 $\alpha$ (23) were used as hosts in cloning experiments and were cultured in 

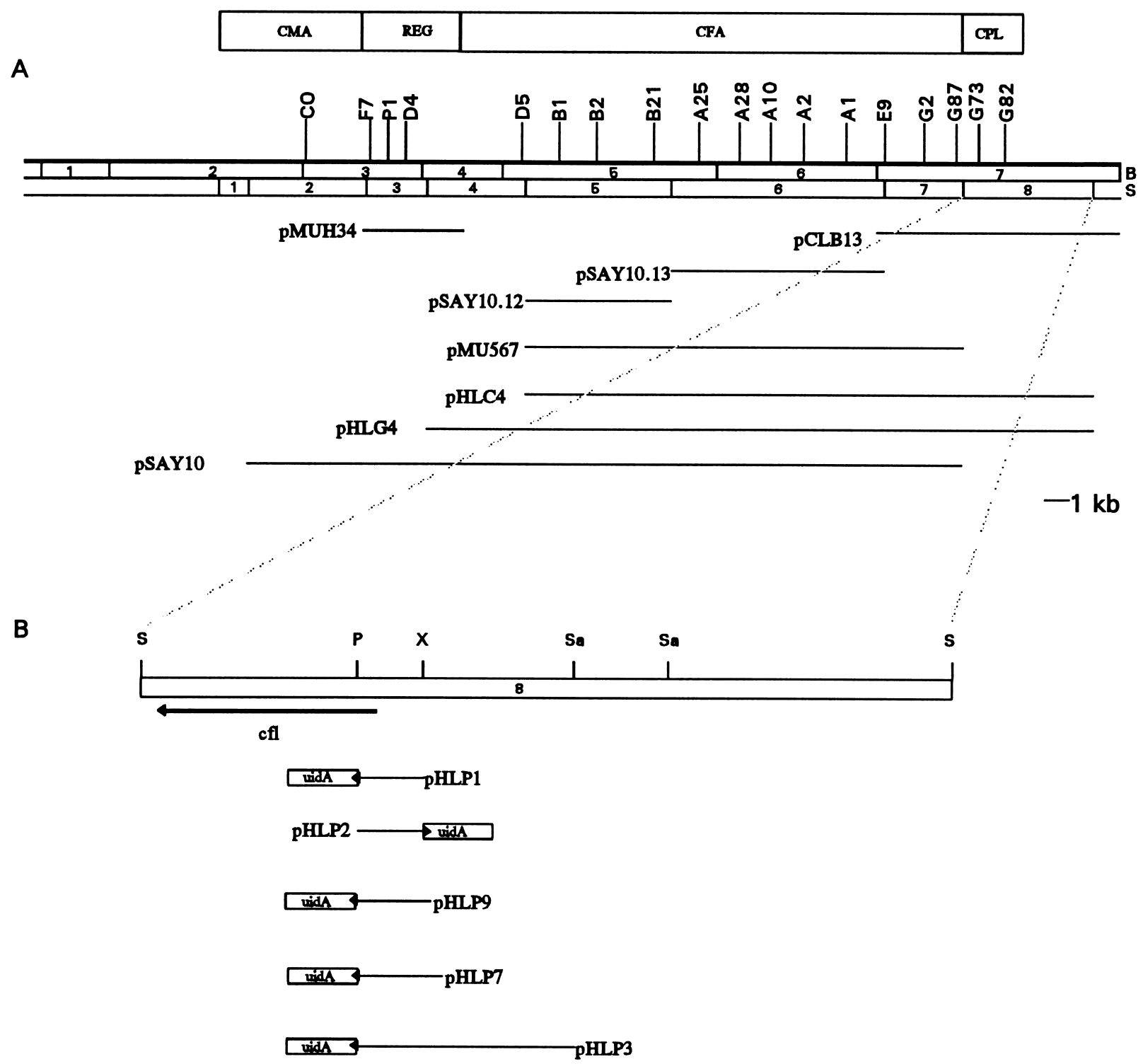

FIG. 1. (A) Physical and functional map of the COR biosynthetic gene cluster in $P$. syringae pv. glycinea PG4180. Vertical lines above the physical map with letter-number designations represent the locations of mutations generated with Tn 5 or antibiotic cassettes. Functional regions of the COR biosynthetic cluster are shown in the rectangles above the physical map and are abbreviated as follows: CMA, CMA biosynthetic gene cluster; REG, regulatory region; CFA, CFA biosynthetic gene cluster; CPL, CPL region (coupling of CFA and CMA via amide bond formation). The horizontal arrow above the functional map indicates the location of the $c f l$ CFA transcript described in this report. The horizontal lines below the physical map show the subclones used for complementation analysis. (B) Physical map of Sst I fragment 8 showing the location of the gene encoding CFA ligase ( $c f$ ) from the transcriptional start site to the translational stop (arrowhead). The locations and orientations of promoter probe constructs used in this study are indicated. Restriction enzymes: B, Bam HI; P, PstI; S, SstI; Sa, SalI; X, XbaI.

Luria-Bertani medium (23) at $37^{\circ}$ C. P. syringae pv. glycinea was routinely cultured on mannitol-glutamate medium $(10)$ at 24 to $26^{\circ} \mathrm{C}$. Derivatives of PG4180 containing transposon or antibiotic cassette insertions in the COR biosynthetic cluster are designated by letter-number combinations (Fig. 1A and Table 1). COR production and GUS activity were assayed in broth cultures of PG4180 grown in Hoitink-Sinden medium optimized for COR production (HSC) (16) on a rotary shaker $(250 \mathrm{rpm})$ at 18 or $28^{\circ} \mathrm{C}$. Antibiotics were added to media in the following concentrations (micrograms per milliliter): ampicillin, 50; kanamycin, 25; streptomycin, 25; spectinomycin, 25; and tetracycline, 12.5. All experiments were repeated at least once.

Molecular and genetic techniques. Agarose gel electrophoresis, restriction digests, PCRs, and small-scale plasmid isolations from $E$. coli were performed by standard procedures (23). Plasmid DNA was isolated from Pseudomonas strains as described previously $(2,5)$. DNA fragments were excised from agarose gels, 
TABLE 1. Bacterial strains and plasmids used in this study

\begin{tabular}{|c|c|c|}
\hline Strain or plasmid & Relevant properties & Reference(s) or source \\
\hline \multicolumn{3}{|l|}{ Escherichia coli } \\
\hline $\mathrm{DH} 5 \alpha$ & & 23 \\
\hline HB101 & & 23 \\
\hline \multirow{2}{*}{\multicolumn{3}{|c|}{$\begin{array}{l}\text { Pseudomonas syringae } \\
\text { pv. glycinea }\end{array}$}} \\
\hline & & \\
\hline PG4180 & $\mathrm{COR}^{+}$; contains $\mathrm{p} 4180 \mathrm{~A}$ & 3 \\
\hline PG4180.A2 & $\mathrm{Km}^{\mathrm{r}} \mathrm{COR}^{-} \mathrm{CFA}^{-} \mathrm{CMA}^{+} \mathrm{CPL}^{+}$ & 31 \\
\hline PG4180.A10 & $\mathrm{Km}^{\mathrm{r}} \mathrm{COR}^{-} \mathrm{CFA}^{-} \mathrm{CMA}^{+} \mathrm{CPL}^{+}$ & 31 \\
\hline PG4180.B21 & $\mathrm{Km}^{\mathrm{r}} \mathrm{COR}^{-} \mathrm{CFA}^{-} \mathrm{CMA}^{+} \mathrm{CPL}^{+}$ & 31 \\
\hline PG4180.C0 & $\mathrm{Km}^{\mathrm{r}} \mathrm{COR}^{-} \mathrm{CFA}^{+} \mathrm{CMA}^{-} \mathrm{CPL}^{+} ; c m a A:: \operatorname{Tn} 5$ & 25,31 \\
\hline PG4180.D4 & $\mathrm{Km}^{\mathrm{r}} \mathrm{COR}^{-} \mathrm{CFA}^{-} \mathrm{CMA}^{-} \mathrm{CPL}^{+l-} ; \operatorname{cor} R:: \operatorname{Tn} 5$ & 28 \\
\hline PG4180.D5 & $\mathrm{Km}^{\mathrm{r}} \mathrm{COR}^{-} \mathrm{CFA}^{-} \mathrm{CMA}^{+} \mathrm{CPL}^{+}$ & 27 \\
\hline PG4180.E9 & $\mathrm{Km}^{\mathrm{r}} \mathrm{COR}^{-} \mathrm{CFA}^{-} \mathrm{CMA}^{+} \mathrm{CPL}^{+}$ & 31 \\
\hline PG4180.F7 & $\mathrm{Km}^{\mathrm{r}} \mathrm{COR}^{-} \mathrm{CFA}^{-} \mathrm{CMA}^{-} \mathrm{CPL}^{+/-} ; \operatorname{cor} P:: \operatorname{Tn} 5$ & 3,28 \\
\hline PG4180.G73 & $\mathrm{Km}^{\mathrm{r}} \mathrm{COR}^{-} \mathrm{CFA}^{-} \mathrm{CMA}^{+} \mathrm{CPL}^{-} ; c f l:: \operatorname{Tn} 5$ & 3,13 \\
\hline PG4180.G82 & $\mathrm{Km}^{\mathrm{r}} \mathrm{COR}^{-} \mathrm{CFA}^{-} \mathrm{CMA}^{+} \mathrm{CPL}^{+}$ & 3 \\
\hline PG4180.G87 & $\mathrm{Km}^{\mathrm{r}} \mathrm{COR}^{-} \mathrm{CFA}^{-} \mathrm{CMA}^{+} \mathrm{CPL}^{+}$ & 3 \\
\hline PG4180.P1 & $\mathrm{Gm}^{\mathrm{r}} \mathrm{COR}^{-} \mathrm{CFA}^{-} \mathrm{CMA}^{-} \mathrm{CPL}^{+/-} ; \operatorname{cor} S:: \operatorname{Tn} 5$ & 28 \\
\hline \multicolumn{3}{|l|}{ Plasmids } \\
\hline pRK415 & $\mathrm{Tc}^{\mathrm{r}}$; RK2-derived cloning vector & 11 \\
\hline pLAFR3 & $\mathrm{Tc}^{\mathrm{r}}$; RK2-derived cosmid vector & 24 \\
\hline $\mathrm{p} 4180 \mathrm{~A}$ & $\begin{array}{l}\text { 90-kb plasmid in } P \text {. syringae pv. glycinea PG4180; contains COR biosynthetic } \\
\text { gene cluster }\end{array}$ & 3 \\
\hline pRG960sd & $\begin{array}{l}\mathrm{Sm}^{\mathrm{r}} \mathrm{Sp}^{\mathrm{r}} ; 17.0 \mathrm{~kb} \text {; contains promoterless uidA with start codon and Shine- } \\
\text { Dalgarno sequence }\end{array}$ & 29 \\
\hline pHL1 & $\mathrm{Tc}^{\mathrm{r}} ; 5.2-\mathrm{kb}$ Sst $\mathrm{I}$ fragment in $\mathrm{pRK} 415$; contains $c f$ and $3.4 \mathrm{~kb}$ of upstream DNA & 3 \\
\hline pHLC4 & $\mathrm{Tc}^{\mathrm{r}} ;$ cosmid clone containing $22 \mathrm{~kb}$ of p4180A DNA & This study \\
\hline pHLG4 & $\mathrm{Tc}^{\mathrm{r}}$; cosmid clone containing $27 \mathrm{~kb}$ of $\mathrm{p} 4180 \mathrm{~A}$ DNA & This study \\
\hline pHLP1 & $\mathrm{Sm}^{\mathrm{r}} \mathrm{Sp}^{\mathrm{r}} ; 0.46-\mathrm{kb}$ XbaI-Pst I fragment from pHL1 in pRG960sd (XbaI-PstI-uidA) & 13 \\
\hline pHLP2 & $\mathrm{Sm}^{\mathrm{r}} \mathrm{Sp}^{\mathrm{r}} ; 0.46-\mathrm{kb}$ XbaI-PstI fragment from $\mathrm{pHL} 1$ in pRG960sd (PstI-XbaI-uidA) & 13 \\
\hline pHLP3 & $\mathrm{Sm}^{\mathrm{r}} \mathrm{Sp}^{\mathrm{r}} ; 1.4-\mathrm{kb}$ SalI-PstI fragment from pHL1 in pRG960sd & This study \\
\hline pHLP5 & $\mathrm{Sm}^{\mathrm{r}} \mathrm{Sp}^{\mathrm{r}} ; 2.5-\mathrm{kb}$ SalI-PstI fragment of pHL1 in pRG960sd & This study \\
\hline pHLP7 & $\mathrm{Sm}^{\mathrm{r}} \mathrm{Sp}^{\mathrm{r}} ; 0.52-\mathrm{kb}$ PstI fragment derived by PCR in pRG960sd & This study \\
\hline pHLP9 & $\mathrm{Sm}^{\mathrm{r}} \mathrm{Sp}^{\mathrm{r}} ; 0.47-\mathrm{kb}$ PstI fragment derived by PCR in $\mathrm{pRG} 960 \mathrm{sd}$ & This study \\
\hline pCLB13 & $\mathrm{Tc}^{\mathrm{r}} ; 10.1-\mathrm{kb}$ Bam HI fragment of p4180A in pRK415 & 3 \\
\hline pSAY10 & $\mathrm{Tc}^{\mathrm{r}}$; pLAFR3 containing $29-\mathrm{kb}$ insert derived from $\mathrm{p} 4180 \mathrm{~A}$ & 31 \\
\hline pSAY10.13 & $\mathrm{Tc}^{\mathrm{r}} ; 8.7-\mathrm{kb}$ Sst I fragment cloned in $\mathrm{pRK} 415$ & 31 \\
\hline pSAY10.12 & $\mathrm{Tc}^{\mathrm{r}} ; 6.0-\mathrm{kb}$ Sst I fragment cloned in $\mathrm{pRK} 415$ & 31 \\
\hline pMU567 & $\mathrm{Tc}^{\mathrm{r}} ; 17.9-\mathrm{kb}$ insert derived from pSAY10 in pLAFR3 & 26 \\
\hline pMUH34 & $\mathrm{Tc}^{\mathrm{r}}$; 3.4-kb HindIII-EcoRI fragment containing regulatory genes & 28 \\
\hline
\end{tabular}

and residual agarose was removed with the GeneClean DNA extraction kit (Bio 101, La Jolla, Calif.). Nonradioactive labeling of DNA fragments and Southern hybridizations were performed as specified in the Genius Labeling and Detection Kit (Boehringer Mannheim, Indianapolis, Ind.). A cosmid library of PG4180 plasmid DNA was constructed in pLAFR3 as described previously (3). Selected plasmids and cosmids were mobilized from $E$. coli to $P$. syringae by a triparental mating method (4), and transconjugants were verified by agarose gel electrophoresis.

pHLP7 and pHLP9 (Table 1) are 0.52- and 0.47-kb PCR products, respectively, cloned into the PstI sites of pRG960sd. The template in each amplification was pHL1. The forward $5^{\prime}$ primers (shown $5^{\prime}$ to $3^{\prime}$ ) were as follows: (i) primer 1 was TAGCTGCAGCGTCCCGATGATAATACTTTGGCG and contained a Pst I recognition site and nucleotides 386 to 411 as reported previously (13); (ii) primer 2 was GTCCTGCAGCGTTACAGAACCGTTCTAGAAAAC and contained a PstI recognition site and nucleotides 443 to 466 (13). The reverse primer (primer 3; also shown 5' to 3') was GATCGCCCGGCTGCAGGCCTTGCA and was the complement of nucleotides 902 to 925 in the previously reported sequence (13). Primers 1 and 3 were used to amplify the $0.52-\mathrm{kb}$ product cloned in pHLP7; primers 2 and 3 were used to amplify the $0.47-\mathrm{kb}$ sequence in pHLP9. All oligonucleotide primers were synthesized by the Oklahoma State University Recombinant DNA/Protein Resource Facility.

Construction of transcriptional fusions and GUS assays. Plasmid pRG960sd (29), which contains a promoterless GUS gene (uidA) downstream of a multiple cloning site, was used to identify and characterize promoter sequences upstream of $c f l$. Subcloned DNA fragments were ligated into pRG960sd, orientations were determined by restriction digests, and constructs were mobilized into Pseudomonas strains via triparental matings. Transcriptional activity was quantified by fluorometric analysis of GUS activity (30) of cells grown for 5 days in $10 \mathrm{ml}$ of HSC broth at 18 or $28^{\circ} \mathrm{C}$. Fluorescence was monitored with a Fluoroskan II version 4.0 microplate reader (ICN Biomedicals, Inc., Costa Mesa, Calif.) in 96-well microtiter plates. Total protein content of cell lysates was determined with the Bio-Rad (Richmond, Calif.) protein assay kit in accordance with the manufacturer's instructions.

Detection of COR. Pseudomonas strains were incubated in 10-ml aliquots of HSC medium at 18 or $28^{\circ} \mathrm{C}$ as described previously (16). Organic acids were extracted from bacterial supernatants, and extracts were analyzed by high-pressure liquid chromatography as described elsewhere (16).

\section{RESULTS}

Cloning and genetic complementation of the CFA biosynthetic region. pCLB13, pSAY10.13, pSAY10.12, pMU567, and pSAY10 are constructs from previous studies (Table 1) which contain various portions of the CFA biosynthetic cluster (Fig. 1A). Strains PG4180.G82, PG4180.G87, PG4180.G2, PG4180. E9, PG4180.A1, PG4180.A2, PG4180.A28, PG4180.A25, PG4180.B21, PG4180.B2, PG4180.B1, and PG4180.D5 (Fig. 1A) are $\mathrm{COR}^{-} \mathrm{CFA}^{-} \mathrm{CMA}^{+} \mathrm{CPL}^{+}$mutants which produce $\mathrm{COR}$ when supplied with exogenous $\mathrm{CFA}(7,27,31)$. G73 is a COR ${ }^{-}$ $\mathrm{CFA}^{-} \mathrm{CMA}^{+} \mathrm{CPL}^{-}$mutant which produces $\mathrm{COR}$ when genetically complemented with the CPL region and supplied with 
TABLE 2. COR production by various $\mathrm{CFA}^{-}$mutants containing cloned regions from the CFA biosynthetic cluster ${ }^{a}$

\begin{tabular}{llllllll}
\hline \multirow{2}{*}{$\begin{array}{l}\text { Mu- } \\
\text { tant }\end{array}$} & \multicolumn{7}{c}{ COR production (mg/liter) } \\
\cline { 2 - 8 } & pCLB13 & pSAY10.13 & pSAY10.12 & pMU567 & pHLC4 & pHLG4 & pSAY10 \\
\hline G82 & $-{ }^{b}$ & NT $^{c}$ & NT & NT & - & 24.6 & NT \\
G73 & - & NT & NT & NT & - & 23.1 & NT \\
G87 & - & NT & NT & - & NT & 22.6 & NT \\
G2 & - & NT & NT & $<1.0^{d}$ & - & NT & NT \\
E9 & - & NT & NT & $<1.0$ & - & 11.6 & - \\
A1 & NT & NT & NT & $<1.0$ & NT & NT & $<1.0$ \\
A2 & NT & - & NT & $<1.0$ & - & 19.0 & $<1.0$ \\
A28 & NT & - & NT & $<1.0$ & NT & NT & $<1.0$ \\
A25 & NT & NT & NT & $<1.0$ & NT & NT & $<1.0$ \\
B21 & NT & NT & - & NT & - & 18.6 & $<1.0$ \\
B2 & NT & NT & - & - & NT & NT & $<1.0$ \\
B1 & NT & NT & - & - & NT & NT & $<1.0$ \\
D5 & NT & NT & NT & NT & - & 28.1 & NT \\
\hline
\end{tabular}

${ }^{a}$ Values are averages of three replicates.

${ }^{b}-$, COR not produced at a detectable level.

${ }^{c} \mathrm{NT}$, COR production not assessed for this mutant-plasmid combination

${ }^{d}$ COR production below $1.0 \mathrm{mg}$ /liter was not considered significant (3).

CFA. When pCLB13, pSAY10.13, pSAY10.12, pMU567, and pSAY10 were introduced into the various $\mathrm{CFA}^{-}$mutants listed in Table 2, COR production either was not observed or occurred at insignificant levels (equal to or less than $2 \%$ of the quantity produced by PG4180). On the basis of these results, we suspected that the CFA biosynthetic cluster might be cotranscribed with the CPL region from a common promoter. Since the $c f$ gene was previously localized within the CPL region and DNA upstream of the $c f$ transcriptional start site was shown to have promoter activity (13), we hypothesized that the CFA biosynthetic cluster was transcribed from the $c f$ promoter. If this assumption was correct, the $c f l$ CFA transcript would initiate in SstI-8 and extend throughout the CFA biosynthetic region.

To test this hypothesis, a library of p4180A DNA was constructed in the BamHI site of pLAFR3 as previously described (3). The following fragments were labeled with digoxigenin and hybridized to cosmid clones from the library: (i) the $1.9-\mathrm{kb}$ $X b a \mathrm{I}-S s t \mathrm{I}$ fragment located on the left side of SstI fragment 8 (Fig. 1B), (ii) SstI fragment 4 (Fig. 1A), and (iii) SstI fragment 5 (Fig. 1A). Southern blot hybridizations to Sst I-digested cosmid DNA indicated that pHLC4 contained SstI fragments 5 to 8 and pHLG4 contained SstI fragments 4 to 8 (Fig. 1A). These two cosmids were evaluated for the ability to restore COR production to mutants defective in CFA production. Although pHLC4 failed to restore COR production to the $\mathrm{CFA}^{-}$mutants tested, introduction of pHLG4 into these mutants resulted in significant COR production, at levels ranging from 11.6 to $28.1 \mathrm{mg} /$ liter (Table 2). These levels approached the quantity of COR produced by wild-type PG4180 in these experiments (approximately $31.9 \mathrm{mg} / \mathrm{liter}$ ).

Characterization of the $c \boldsymbol{l}$ promoter region. We previously reported that the 311-bp region upstream of the $c f l$ transcriptional start site contained promoter activity (13). This was shown with a construct designated pHLP1 (Fig. 1B), which contained the 311-bp region upstream of a promoterless GUS gene. pHLP2, a construct containing this region in the inverse orientation relative to pHLP1 (Fig. 1B), did not promote uidA transcription (13), thereby establishing the transcriptional direction as right to left, as indicated for pHLP1 (Fig. 1B).

In the present study, we further delimited the $c f$ promoter by fusing various amounts of DNA upstream of $c f$ to the promoterless uidA gene in pRG960sd (Fig. 1B). Interestingly, PG4180 transconjugants containing pHLP3, pHLP5, and pHLP7 were 25 to 30 times more active at $18^{\circ} \mathrm{C}$ in the GUS assay than was PG4180(pHLP1) (Table 3). However, GUS activity in PG4180(pHLP9) was not significantly different from that expressed by PG4180(pHLP1) (Table 3). pHLP9 lacks an additional 57 bp of upstream DNA which is present in pHLP7, emphasizing the importance of this region in transcriptional activation of the $c f$ promoter.

Previous studies indicated that the $\mathrm{cmaA}$ and $\operatorname{corS}$ promoter regions are regulated at the transcriptional level by temperature, showing maximal activity at $18^{\circ} \mathrm{C}$ and significantly lower activity at $28^{\circ} \mathrm{C}(25,28)$. In the present study, we incubated PG4180 transconjugants containing pHLP3, pHLP5, and pHLP7 at 18 and $28^{\circ} \mathrm{C}$ and measured GUS activity. Transcriptional activity was approximately fivefold higher when cells were incubated at $18^{\circ} \mathrm{C}$ than when they were incubated at $28^{\circ} \mathrm{C}$ (Table $3)$, demonstrating that the $c f$ promoter resembles the $c m a A$ and corS promoters in its response to temperature.

Transcriptional activation of the $\boldsymbol{c f t} / \mathbf{C F A}$ operon. pMUH34, which contains all of $S s t \mathrm{I}-3$ and a portion of $S s t \mathrm{I}-4$ (Fig. 1A), contains three genes (corR, $\operatorname{cor} S$, and $\operatorname{cor} P$ ) which presumably function as a modified two-component regulatory system (28). PG4180 derivatives containing mutations in these genes were $\mathrm{CFA}^{-} \mathrm{CMA}^{-}$and produced low levels of COR when supplied with exogenous CFA and CMA (1), indicating that CPL activity was not completely abolished. However, the level of COR synthesized in these feeding experiments was extremely low (1), indicating that coupling activity was also reduced in the regulatory mutants.

Recently, Ullrich et al. (28) showed that corR, corS, and $\operatorname{cor} P$ are required for transcriptional activation of the $\mathrm{cmaA}$ promoter, thereby explaining why CMA biosynthesis was inactivated in the regulatory mutants. The elimination of CFA biosynthesis and reduced CPL activity in these mutants suggested that the regulatory region might also function in transcriptional activation of the $c f$ promoter. To explore this possibility, expression of GUS activity in transconjugants containing pHLP3 (cfl::uidA) was investigated. GUS activities for wild-type PG4180 and three regulatory mutants (PG4180.F7, PG4180.P1, and PG4180.D4) containing pHLP3 were compared at 18 and $28^{\circ} \mathrm{C}$ (Fig. 2A). GUS activity was quite high in PG4180(pHLP3) incubated at $18^{\circ} \mathrm{C}$ and approximately fourfold lower when this construct was incubated at $28^{\circ} \mathrm{C}$ (Fig. 2A). GUS activity was negligible in PG4180.F7(pHLP3), PG4180.P1(pHLP3), and PG4180.D4(pHLP3) at both temperatures (Fig. 2A), suggesting that these mutants are defective in transcriptional activa-

TABLE 3. GUS activity in PG4180 transconjugants containing different c fl::uidA transcriptional fusions

\begin{tabular}{lrr}
\hline \multirow{2}{*}{$\begin{array}{c}\text { PG4180 } \\
\text { transconjugant }\end{array}$} & \multicolumn{2}{c}{$\begin{array}{c}\text { Mean GUS activity } \\
\text { (U/mg of protein) }\end{array}$} \\
\cline { 2 - 3 } & $18^{\circ} \mathrm{C}$ & $28^{\circ} \mathrm{C}$ \\
\hline pHLP1 & 4.7 & 2.6 \\
pHLP3 & 146.1 & 26.5 \\
pHLP5 & 150.8 & 28.2 \\
pHLP7 & 125.2 & 23.2 \\
pHLP9 & 10.6 & 6.4 \\
pHLP2 & 0.7 & 1.0 \\
\hline
\end{tabular}

${ }^{a}$ Mean of three replicates per temperature. One unit equals $1 \mu \mathrm{mol}$ of methylumbelliferone formed per min.

${ }^{b}$ PG4180 containing pHLP2 was included as a negative control. In pHLP2, uid $A$ was oriented in the transcriptionally inactive direction relative to the $c f$ promoter (Fig. 1B). 


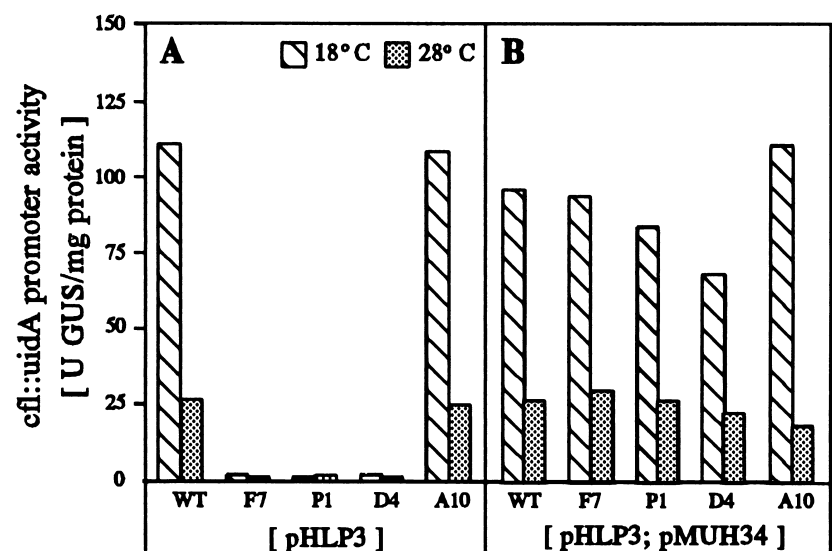

FIG. 2. Effects of temperature and genetic background on $c f::$ uidA promoter activity in $P$. syringae. GUS activity is shown for transconjugants harboring pHLP3 (A) and pHLP3 and pMUH34 (B). WT, wild-type PG4180. Strains PG4180.F7, PG4180.P1, and PG4180.D4 are defective in the regulation of the COR biosynthetic cluster and contain mutations in $\operatorname{cor} P$, cor $S$, and $\operatorname{cor} R$, respectively. Strain PG4180.A10 contains a Tn5 insertion in the CFA biosynthetic cluster. The quantities shown are averages of three replicates.

tion of the cfl::uidA promoter. As controls, we investigated the GUS activity of pHLP3 in PG4180.C0 and PG4180.A10, which contain Tn5 insertions in the CMA and CFA biosynthetic clusters, respectively (3). Unlike the results obtained with the three regulatory mutants, GUS activity in strains PG4180.A10 (pHLP3) (Fig. 1A) and PG4180.C0(pHLP3) (data not shown) was similar to that observed for strain PG4180(pHLP3).

To investigate whether pMUH34 could restore activation of the $c f$ promoter to the regulatory mutants, this clone was introduced into mutants containing pHLP3 (Fig. 2B). Introduction of pMUH34 into PG4180.F7(pHLP3), PG4180.P1 (pHLP3), and PG4180.D4(pHLP3) resulted in GUS activity comparable to that of PG4180(pHLP3) at both temperatures (Fig. 2B), indicating that the regulatory genes encoded by pMUH34 are definitely involved in transcriptional activation of the $c f l$ promoter.

\section{DISCUSSION}

Genetic complementation of CFA-defective mutants revealed that only pHLG4 contained all of the genes necessary for CFA biosynthesis. The 27-kb region cloned in pHLG4 includes the CFA biosynthetic region (localized in SstI fragments 4 to 7), $c f l$, and the upstream promoter region. Although both pHLC4 and pSAY10 contain the structural information required for CFA biosynthesis, only pHLG4 complemented the $\mathrm{CFA}^{-}$mutants. Therefore, the failure of pSAY10 to complement $\mathrm{CFA}^{-}$mutants is likely due to the absence of the promoter region in this construct since $\mathrm{Cfl}$ presumably functions to adenylate CFA for subsequent ligation to CMA and has no known role in CFA biosynthesis (13). The data presented in this report indicate that the CFA biosynthetic gene cluster is organized with $c f l$ in a polycistronic operon. By using a common promoter to transcribe genes for synthesis of CFA and its activation and ligation to CMA, the bacterium has optimized the production of the phytotoxic end product, COR, and minimized production of the nontoxic intermediate CFA. This genetic organization is consistent with the observation that COR is the most abundant coronafacoyl compound produced by PG4180 (31).

The sequence of events in CFA biosynthesis remains fairly obscure, and sequence data within the CFA biosynthetic clus- ter are limited. However, nucleotide sequence analysis of Sst I fragment 7 has revealed the presence of two discrete open reading frames with a probable role in CFA biosynthesis. One open reading frame showed relatedness to acyl carrier proteins, and the second open reading frame resembled $\beta$-ketoacyl synthases (22). Polyketide synthetases are generally classified into type I and II systems and consist of protein complexes that act on covalently bound substrates that are attached as thioesters to an acyl carrier protein (9). The identification of two distinct open reading frames within the CFA biosynthetic gene cluster with a probable role in CFA biosynthesis suggests that the CFA polyketide synthase more closely resembles the type II system, in which discrete polypeptides associate in a complex (9). This is a bit surprising, since most type II polyketide synthases catalyze the synthesis of aromatic polyketides (9) and CFA has a fairly reduced structure. This anomaly may arise from the fact that most published polyketide synthase sequences are for antibiotics produced by streptomycetes and other gram-positive organisms. Although pseudomonads make a number of antifungal compounds from the polyketide pathway $(6,7)$, we are unaware of any published sequence information for these compounds.

The results obtained in the present study with $c f l:$ uid $A$ transcriptional fusions clearly showed that $c f$ is regulated at the transcriptional level by temperature and requires functional copies of $\operatorname{corR}$, cor $S$, and $\operatorname{cor} P$. The $\operatorname{cmaA}$ and $\operatorname{cor} S$ promoters also share these characteristics $(25,28)$. Several schemes were recently proposed to explain how CorS, CorR, and CorP might function in the transcriptional activation of the COR biosynthetic gene cluster. The scenarios proposed by Ullrich et al. (28) each involve the autophosphorylation of CorS, a putative histidine protein kinase, at the inducing temperature $\left(18^{\circ} \mathrm{C}\right)$. CorS would then phosphorylate CorR and CorP, which both show relatedness to response regulators in the $\mathrm{RO}_{\mathrm{III}}$ group (18). Phosphorylated CorR and CorP would then function in concert or sequentially to activate transcription of the corS, $c m a A$, and $c f$ promoters. CorR contains a helix-turn-helix motif (28) and could conceivably bind and activate transcription of promoter regions in the COR biosynthetic gene cluster. Therefore, the three temperature-regulated promoters might contain a consensus sequence for recognition of a shared transcriptional activator, such as CorR. To investigate this possibility, the $c f, c m a A$, and $c o r S$ promoter regions were compared by BESTFIT analysis (University of Wisconsin Genetics Computer Group). Alignment of the three sequences revealed a series of conserved bases in the three promoter regions, including a 5-bp sequence (CAGCG) (Fig. 3). Furthermore, the 60-bp sequence shown in Fig. 3 for $c f l$ is present in pHLP7 but

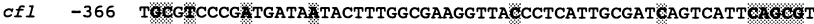 CMAA -798 GECAFGTAARCCATGAGCTCAGCAAACTCGATCAGATCTTCGAGGECATTTTTCAECET

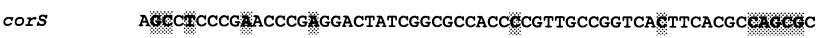

FIG. 3. Alignment of 60-bp regions from the $c f l, c m a A$, and corS promoter regions. The 60-bp sequence shown for $c f l$ was previously published (13) and is present in pHLP3, pHLP5, and pHLP7, three $c f::$ uid $A$ fusions which showed high levels of GUS activity in PG4180 transconjugants incubated at $18^{\circ} \mathrm{C}$ (Table 3 ). This sequence was not present in pHLP1 and pHLP9, which were significantly less active than the former three constructs in GUS assays. The activity of the $c f$, $c m a A$, and $\operatorname{cor} S$ promoters requires functional copies of $\operatorname{cor} P$, corR (putative response regulators [28]), and corS (putative histidine protein kinase [28]). The transcriptional start sites for $c f l$ and $c m a A$ have been established by primer extension $(13,25)$, and the numbers on the left indicate the locations of the sequences relative to the transcriptional start site. The transcriptional start site for cor $S$ has not been determined. The sequence cited above is located approximately 250 bp upstream of the corS translational start and within the promote region previously defined by progressive subcloning in pRG960sd (28). Shaded areas indicate identical bases in the three promoter regions. 
absent from pHLP9. PG4180(pHLP7) was approximately 12.5 times more active in GUS assays than was PG4180(pHLP9) when incubated at $18^{\circ} \mathrm{C}$ (Table 3 ), providing additional support for the role of this conserved region in transcriptional activation of the $c f$ promoter. We are currently evaluating whether CorR binds to the regions shown in Fig. 3 by using gel retardation and footprinting assays with purified CorR.

Optimal production of COR, CFA, and CMA occurs at $18^{\circ} \mathrm{C}$, and data presented in this and other studies (28) suggest that the underlying mechanism for temperature regulation is the modified two-component regulatory system. Although the role of temperature in the expression of virulence genes in human and animal pathogens is well established (14), thermoregulated gene expression in plant-associated bacteria is not well understood. In Agrobacterium tumefaciens, elevated temperatures were shown to decrease autophosphorylation of VirA (a histidine protein kinase) and subsequent phosphorylation of VirG (transcriptional activator of vir genes), thereby resulting in decreased tumor formation (8). It is possible that temperature might function in a similar manner to modulate the proposed phosphorylation activities of CorS. Alternatively, temperature might modulate the activity of the putative response regulators, CorR and CorP. For example, in Klebsiella pneumoniae, the transcriptional activator NifA is heat labile and unable to catalyze transcriptional activation of the nifHDK promoter (12). Efforts to obtain CorP, CorR, and CorS in purified form are currently under way, and these proteins will be used to elucidate the mechanisms involved in thermoregulation of the COR biosynthetic cluster.

\section{ACKNOWLEDGMENTS}

M.U. acknowledges support from the German Academic Exchange Service (DAAD). This work was supported by the Oklahoma Agricultural Experiment Station and by NSF grants INT-9220628 and MCB9316488

\section{REFERENCES}

1. Bender, C., H. Liyanage, D. Palmer, M. Ullrich, S. Young, and R. Mitchell. 1993. Characterization of the genes controlling biosynthesis of the polyketide phytotoxin coronatine including conjugation between coronafacic acid and coronamic acid. Gene 133:31-38.

2. Bender, C. L., and D. A. Cooksey. 1986. Indigenous plasmids in Pseudomonas syringae pv. tomato: conjugative transfer and role in copper resistance. J. Bacteriol. 165:534-541.

3. Bender, C. L., and D. A. Cooksey. 1987. Molecular cloning of copper resistance genes from Pseudomonas syringae pv. tomato. J. Bacteriol. 169:470474

4. Bender, C. L., S. A. Young, and R. E. Mitchell. 1991. Conservation of plasmid DNA sequences in coronatine-producing pathovars of Pseudomonas syringae. Appl. Environ. Microbiol. 57:993-999.

5. Crosa, J. H., and S. Falkow. 1981. Plasmids, p. 266-282. In P. Gerhardt, R. G. E. Murray, R. N. Costilow, E. W. Nester, W. A. Wood, N. R. Krieg, and G. B. Phillips (ed.), Manual of methods in general bacteriology. American Society for Microbiology, Washington, D.C.

6. Cuppels, D. A., C. R. Howell, R. D. Stipanovic, A. Stoessl, and J. B. Stothers. 1986. Biosynthesis of pyoluteorin: a mixed polyketide-tricarboxylic acid cycle origin demonstrated by $\left[1,2-{ }^{13} \mathrm{C}_{2}\right]$ acetate incorporation. $\mathrm{Z}$. Naturforsch. Teil C 41:532-536.

7. Feline, T. C., R. B. Jones, G. Mellows, and L. Phillips. 1977. Pseudomonic acid. Part 2. Biosynthesis of pseudomonic acid A. J. Chem. Soc. Perkin Trans. I 1977:309-318.

8. Jin, S., Y. N. Song, W. Y. Deng, M. T. Gordon, and E. Nester. 1993. The regulatory VirA protein of Agrobacterium tumefaciens does not function at elevated temperatures. J. Bacteriol. 175:6830-6835.

9. Katz, L., and S. Donadio. 1993. Polyketide synthesis: prospects for hybrid antibiotics. Annu. Rev. Microbiol. 47:875-912.

10. Keane, P. J., A. Kerr, and P. B. New. 1970. Crown gall of stone fruit. II. Identification and nomenclature of Agrobacterium isolates. Aust. J. Biol. Sci. 23:585-595.

11. Keen, N. T., S. Tamaki, D. Kobayashi, and D. Trollinger. 1988. Improved broad-host-range plasmids for DNA cloning in gram-negative bacteria. Gene 70:191-197.

12. Lee, H., D. K. Burger, and S. Kustu. 1993. Activity of purified NIFA, a transcriptional activator of nitrogen fixation genes. Proc. Natl. Acad. Sci. USA 90:2266-2270.

13. Liyanage, H., C. Penfold, J. Turner, and C. L. Bender. 1995. Sequence, expression and transcriptional analysis of the coronafacate ligase-encoding gene required for coronatine biosynthesis by Pseudomonas syringae. Gene 153:17-23.

14. Mekalanos, J. J. 1992. Environmental signals controlling expression of virulence determinants in bacteria. J. Bacteriol. 174:1-7.

15. Mitchell, R. E., S. A. Young, and C. L. Bender. 1994. Coronamic acid, an intermediate in coronatine biosynthesis by Pseudomonas syringae. Phytochemistry 35:343-348.

16. Palmer, D. A., and C. L. Bender. 1993. Effects of environmental and nutritional factors on production of the polyketide phytotoxin coronatine by Pseudomonas syringae pv. glycinea. Appl. Environ. Microbiol. 59:1619-1626.

17. Palmer, D. A., and C. L. Bender. Unpublished data.

18. Parkinson, J. S., and E. C. Kofoid. 1992. Communication modules in bacterial signalling proteins. Annu. Rev. Genet. 26:71-112.

19. Parry, R. J., M. T. Lin, A. E. Walker, and S. Mhaskar. 1991. The biosynthesis of coronatine: investigations of the biosynthesis of coronamic acid. J. Am. Chem. Soc. 113:1849-1850.

20. Parry, R. J., and R. Mafoti. 1986. Biosynthesis of coronatine, a novel polyketide. J. Am. Chem. Soc. 108:4681-4682.

21. Parry, R. J., S. V. Mhaskar, M. T. Lin, A. E. Walker, and R. Mafoti. 1994. Investigations of the biosynthesis of the phytotoxin coronatine. Can. J. Chem. 72:86-99.

22. Penfold, C., C. L. Bender, and J. G. Turner. Unpublished results

23. Sambrook, J., E. F. Fritsch, and T. Maniatis. 1989. Molecular cloning: a laboratory manual, 2nd ed. Cold Spring Harbor Laboratory Press, Cold Spring Harbor, N.Y.

24. Staskawicz, B., D. Dahlbeck, N. Keen, and C. Napoli. 1987. Molecular characterization of cloned avirulence genes from race 0 and race 1 of Pseudomonas syringae pv. glycinea. J. Bacteriol. 169:5789-5794.

25. Ullrich, M., and C. L. Bender. 1994. The biosynthetic gene cluster for coronamic acid, an ethylcyclopropyl amino acid, contains genes homologous to amino acid-activating enzymes and thioesterases. J. Bacteriol. 176:75747586.

26. Ullrich, M., and C. L. Bender. Unpublished data.

27. Ullrich, M., A. C. Guenzi, R. E. Mitchell, and C. L. Bender. 1994. Cloning and expression of genes required for coronamic acid (2-ethyl-1-aminocyclopropane 1-carboxylic acid), an intermediate in the biosynthesis of the phytotoxin coronatine. J. Bacteriol. 60:2890-2897.

28. Ullrich, M., A. Peñaloza-Vázquez, A.-M. Bailey, and C. L. Bender. 1995. A modified two-component regulatory system is involved in temperature-dependent biosynthesis of the Pseudomonas syringae phytotoxin coronatine. J. Bacteriol. 177:6160-6169.

29. Van den Eede, G., R. Deblaere, K. Goethals, M. V. Montagu, and M. Holsters. 1992. Broad host range and promoter selection vectors for bacteria that interact with plants. Mol. Plant-Microbe Interact. 5:228-234.

30. Xiao, Y., Y. Lu, S. Heu, and S. W. Hutcheson. 1992. Organization and environmental regulation of the Pseudomonas syringae pv. syringae $61 \mathrm{hrp}$ cluster. J. Bacteriol. 174:1734-1741.

31. Young, S. A., S. K. Park, C. Rodgers, R. E. Mitchell, and C. L. Bender. 1992 Physical and functional characterization of the gene cluster encoding the polyketide phytotoxin coronatine in Pseudomonas syringae pv. glycinea. J. Bacteriol. 174:1837-1843. 